wien cholera has usually broken out in that city (June 17th to July 15th). The subsoil water then rises gradually till it reaches its maximum in November, by which time cholera has usually disappeared from Egypt.

TABLE II.

\begin{tabular}{|c|c|c|c|c|c|}
\hline 1890. & 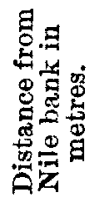 & 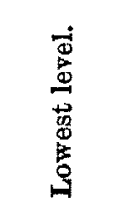 & 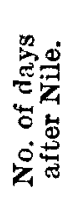 & 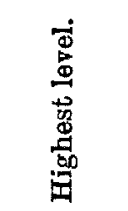 & 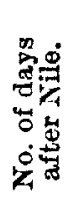 \\
\hline Nile at Rodah .. .. .. & .. & June 15 & . & Sept. 28 & . \\
\hline Well in Ezbekieh quarter & $* 500$ & July 8 & 23 & Oct. 31 & 33 \\
\hline Well at Sanitary Offices & 650 & July 23 & 38 & Dec. 5 & 68 \\
\hline 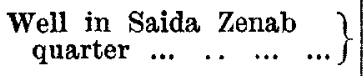 & 1000 & July 28 & 43 & Dec. 10 & 73 \\
\hline Well in Khalifa quarter & 2050 & Aug. 7 & 53 & Jan. 14 & 108 \\
\hline
\end{tabular}

Influence of the Nile.-There is a popular belief in Egypt that cholera never breaks ont after the Nile has risen. If this means that it does not appear in any given town after the rise there, it is manifestly without foundation ; but if it means that cholera does nct explode after the Nile flood has reached the Delta, it is true. If we remember that every town in Egypo is supplied with drinking water either from the Nile direct or from its canal branches, it is quite obvious that the rapid flow in great volume of the annual rise must very greatly affect the health of the inhabitants. It is probably the flood of August and the following montbs which drives cholera out of the country. An average Nile is at its lowest at Cairo about June $17 \mathrm{th}$, and its rise is then so gradual as to be unimportant till the middle of July. In 1883 the river was very low until the rise began at Cairo on July 1st, and this rise would not reach Damietta in any perceptible form till at least July 10th. It would take another month before it could purify the water-supply, and it was then that cholera ceased to ravage the town. Synchronous with the Nile flood is a healthful north wi. $d$ which blows up the river, and must be of use in dispelling disease. Table III. shows that the Nile reached a very low level before its rise in five cholera years, and this, with its consequent effects on subsoil drainage, must certainly have had a very ill-predisposing effect. Also, it should be noticed, that in 1855 , as in 1883 , the rise was late in coming, and the Delta would, therefore, have an extra fortnight of very bad drinking water. In 1865 , on the other hand, the Nile was neither abnormally low nor late. The arrival of the Nile flood is, of course, not sufficient to prevent the outbreak of cholera, but it may be noticed that Upper Egypt, which gets its rise two weeks or more before Cairo, is affected by cholera some days after Cairo ; but the presence of cleaner water in bulk may very likely modify the severity of the disease in the towns above Cairo.

TABLE III.

Remarks on the Nile gauge at Cairo.

\begin{tabular}{|c|c|c|c|c|}
\hline $\begin{array}{l}\text { Cholera } \\
\text { years. }\end{array}$ & $\begin{array}{l}\text { Date of } \\
\text { rise. }\end{array}$ & \multicolumn{2}{|c|}{$\begin{array}{l}\text { Lowest level before } \\
\text { rise. }\end{array}$} & Remarks. \\
\hline & & Cubits. & Digits. & \\
\hline $\begin{array}{l}1831 \\
1834\end{array}$ & \multicolumn{3}{|c|}{ Not known. } & \\
\hline 1837 & - & 5 & 8 & Extremely low. \\
\hline 1840 & - & 7 & 16 & Good. \\
\hline 1848 & June 13 & 5 & 14 & Extremely low. \\
\hline 1849 & June 21 & 5 & 11 & Extremely low. \\
\hline 1850 & June 18 & 5 & 11 & Extremely low. \\
\hline 1855 & July 1 & 7 & 12 & Good. \\
\hline 1865 & June 7 & 7 & 11 & Good. \\
\hline 1866 & June 27 & 7 & 21 & Good. \\
\hline 1883 & July 1 & 6 & 22 & Rather low. \\
\hline
\end{tabular}

Cattle Plague.-Bovine typhus immediately preceded the cholera of 1883 , and may have had something to do with the poisoning of the water-supply owing to the careless habits of the pearantry in thus dispcsing of carcases, and also may have been one of the canses of the diarrboa and vomiting which in some places anticipated the epidemic. The fellah, looking on meat foud as a rare treat, was ody too glad to eat the diseased cattle which had been slaughtered by veterinary order. I have thought it would be interesting to see whether cattle plague had any con. nexion with previous cholera epidemics, but of this there is no proof. The cattle plague was introduced from Southern Russia into Egypt in 1841, and, raging till 1843, is calcu. lated to have destroyed 665,000 head during the three years. In 1863 there was another visitation, and it was reckoned that 734,642 cattle died, and were mostly thrown into the Nile, ${ }^{8}$ but none of these were cholera years in Egypt. From what we know of native methods of stamping cut disease, we may assume that it was still present in the country in 1865, but no writers on cholera have referred to it. ${ }^{9}$ In 1881 the plague was again intro. duced into Egypt by Russian cattle, and lasted till the serious epidemic of it in 1883. In April, 1884, it was reported from Upper and Lower Egypt, and I found it myself in Cairo. We persuaded the Government to pass some urgent regulations, and prevented the import of all cattle from infected countries, such as Russia and Syria. Since then the disease has been unknown in Egypt.

[Errata.-The following misprints in the previous part of this article require correction:- $P$. 602, line 27 from bottom of second column, for " existence" read mention p. 602, line 12 from bottom of second column, for " 1844 " read 188.4 ; p. 602 , line 11 from bottom of second column, omit " had"; p. 603, line 11 from top of second column, for "to" read and; p. 603, line 19 from top of second column, for "disinfectant" read disinfectants; p. 603, line 40 from top of second column, for "Ramadam" read Ramadan: p. 604, line 13 from top of first column, for "impossibly" read absolutely.]

\section{THE PERMANENT CURE OF STRICTURE BI EXTERNAL URETHROTOMY.}

By C. W. MANSELL MOULLIN, F.R C S ENG., \&., SLRGEON AND LECTCRER ON PHYSIOLOGY TO THE LONDON HOSPITAL.

Is August, 1889, a patient forty-five years of age was admitted under my care at the London Hospital suffering from an attack of synovitis of the knee-joint. In the course of inquiry he informed me that eighteen years before he had been operated upon for stricture by a Dr. South, of the City.road, who had died many years ago. Previously to this he had suffered a great deal of trouble with his urethra; on several occasions he had been unable to pass his urine, and he had frequently been obliged to apply to hospital for relief. Since the operation he had not experienced the least inconvenience, and he had never passed an instrument for himself or taken any other pre. caution. With regard to the nature of the operation, he was quite clear that he had been cut from the outside. Having obtained permission to examine him, I found a linear scar in the middle line of the perineum, about an inch and a half in lengtb, just such a one as would have been left by external urethrotomy. There was no induration about it, and the tissues were perfectly flexible. On trying a catheter, I found that a No. 12 English entered the bladder without difficulty, and without even giving the sensation of passing over a rough surface. In other words, external urethrotomy had been performed eighteen years before on a very bad case of stricture, and the patient had been cured. I use the term "cured" advisedly. I am aware that the curability of stricture has been denied; I was taught so myself, and I have taught others so ; but I have seen very good reason to alter my opinion.

In another case under my care, although the length of time was not nearly so great, the result was scarcely less instructive. The patient, who wes fifty years of age, and weighed eighteen stones, had for many years suffered from a stricture, which had at last culminated in an

Fleming : Animal Plagues, London, 1882, p. 499 9 Colucci Bey: 'Typhoid fever was very provalent in 1863 
abscess and a perineal fistula. Dilatation had been practised twice with benefit, so far as the size of the stream was concerned. Holt's dilator had been used on another occasion, and the patient was in the habit of passing a catheter for himself. In spite of everything, however, there was a continuous gleet, and the fistula refused to close. At the time of admission a No. 11 English catheter passed fairly easily; but the urethra, although the stream of urine was of good size, was practically strictured. The walls were hard and rigid ; the catheter rubbed and grated against them as it passed down; and when the urethrameter was used it was evident at once that, instead of all the tissues around being soft and yielding, as they should have been, they were as hard and resistant as cartilage. The external orifice of the fistula was in the middle line of the perineum, ly iug in the centre of an indurated mass that filled up the space between the anus and the scrotum; and though the amount of urine that came through it was not very great, it showed no sign of diminishing. External urethrotomy was performed in August, 1888. The urethra lay at a depth of nearly three inches from the surface, the whole of the space between being filled with a dense mass of cicatricial tissue, in which no trace of any of the normal structures could be distinguished; the cut section looked like that of scirrhus more than anything else. For some days the whole of the urine came through the perineum, and the wound suppurated freely, but there was no rigor or constitutional dis turbance. At the end of a week a No. 12 English catheter was passed. In a fortnight the incision was almost healed, and in place of the hard mass that projected above the level of the tissues around, there was a sofo pliable cicatrix, so thin that a catheter in the urethra could be distinctly felt from the outside. Eighteen months after the operation there was no evidence of recontraction, and the fistula remained sound. The patient bad passed a catheter once or twice in the interval, as he expressed it, to make sure that every thing was free.

The length of time in such a case as this is of course much too short for any definite conclusion, and the patient to some extent lessened the importance of the case by passing a catheter for himself (so far as I could ascertain he only did it on four occasions), but the fact remained that recontraction had not commenced, and what is in my opinion of still greater importance the tissues retained their pliability; the dense cicatricial mass that surrounded the urethra and prevented the walls from regaining their natural character had completely disappeared. In addition to these, I have the notes of three other cases (varying in duration from one year and three months to two years) in which the history and the result are essentially the same.

This experience of mineis by nomeansunique. The firstcase mentioned by Syrne is equally striking. Dilatation had been practised on several occasions; internal urethrotomy had been performed twice, and various other measures had been tried without obtaining more than a very transient degree of I relief. External urethrotomy was performed, and thirteen years after there was no sign of recontraction, although in the meanwhile none of the usual steps had been taken to prevent it; and similar histories, only of shorter duration, are recorded of many others under his care. One in particular is of great importance, as two years later a post-mortem examination was made, and it was demonstrated that not only was the urethra not diminished in diameter at the site of the old stricture, but it was actually widened; there was a funnel-shaped dilatation on the floor, as if the cicatrix had yielded under the pressure of the urine.

Harrison records a closely similar occurrence. In 1867 Bickersteth performed Syme's operation for traumatic stricture and urinary fistula of the worst type; in 1869 the man was known to be quite well, although nothing had been done to prevent recontraction. After his death in 1885 the urethra was removed and examined, and no sign of the stricture could be found ; in fact, the urethra, as in Syme's case; quoted above, is described as being dilated in proportion to the rest. Other observations of like character have been recorded from time to time, but I do not think any more is needed to establish the fact that some of the very worst strictures, involving the deep part of the urethra, traumatic as well as gonorrhceal, with fistulæ or without, are in certain circumstances curable, - that is to say, after the lapse of many years they do not show the least tendency to recontract.

The pathological anatomy of these strictures furnishes, I believe, a reasonable explanation both of the success that ttends external urethrotomy and the failure, more or less complete, of all other methods. Strictures that implicate the posterior part of the corpus spongiosum and the bulb and these are practically the only ones with which external urethrotomy is concerned) present two different stages. In the one the irritant is superficial, and the mucous and sub mucous layers are the only structures involved. The soft spiral folds into which the lining of the urethra is thrown when it collapses are welded together : the wall is rigid and unyielding, and the canal constricted, but the structures around are scarcely affected; the stricture is urethral, only. In the other it is peri-urethral as well ; the specific gonococcus, acting upon the mucous membrane, is no longer the only irritant; there is in addition an obstruction to the passage of urine, and with every act of micturition all the soft tissues that surround the canal are strained and stretched. As a result a large and constantly increasing amount of lymph is poured out, not in the submucous tissue only, but around the urethra, and especially below it: the interstices in the corpus spongiosum and the bulb are filled first; then, as the induration spreads, the tissues farther and farther away; until at length the urethra is invested by a mass of organised lymph as dense and hard as cartilage. Dissection shows the difference at once. In a urethral stricture the layers of fascia covering in the corpus spongiosum and the accelerator urinæ are distinct and well defined; the erectile tissue is unaffected, and there is no induration until the submucous layer is reached. In a periurethral one, on the other hand, the skin and superficial fascia are possibly unaffected (even they are often bound together by adhesions), but this is certainly not true of anything else. The deep faecia is thickened and fused inseparably with the tissues beneath; an incision in it does not gape or yield; the muscular fibres are thin and wasted; in many parts they are only to be recognised with difficulty, and the erectile tissue is so condensed and hardened that it scarcely bleeds when it is cut. In other words, owing to the constant irritation maintained by the urethral stricture, the corpus spongiosum and the structures around it are kept in a state of chronic inflammation; more and more lymph is poured out; all the interstices are filled with the inflammatory exudation, and the normal tissues are compressed and starved.

How long it is before the peri-urethral tissues become affected depends upon a variety of circumstances. Traumatic strictures in which suppuration has occurred, and gonorrhceal ones in which the infection is repeated again and again, may do so within a few months. On the other hand, years may pass before it happens. So far as treatment is concerned, it is more to the point that in most instances the distinction can be recognised at once. The density of the tissues in the middle line of the perineum varies in different people and at different ages, but if the corpus spongiosum or the bulb stands out distinctly, or if the consistence is uneven, one part feeling harder and more tender than the rest, nothing more is required. No measure that aims at less than the absorption of the whole of this inflammatory exudation has a chance of permanent success. The only hope of effecting a cure is to remove the original irritant (without substituting another in its place) and to give all the tissues around the urethra perfect physiological rest until they have recovered their normal state of nutrition and freed themselves from the lymph that infiltrates them. This can be done by external urethrotomy, and it cannot be done by any thing else.

Mechanical dilatation cannot succeed in a peri-urethral stricture. Pressure undoubtedly causes the absorption of recent lymph, but it cannot influence such widely diffused exudation without a degree of force that would do more harm than good. Continuous dilatation is equally in. effectual. How it acts is not quite certain ; apparently the irritation it sets up leads to hyperæmia and rapid softening of the dense tissue lying near; but this (and experience fully confirms it) can only end, as soon as the irritant is removed, in fresh condensation and recontraction on a scale even worse than before.

Electrolysis is no better. A cicatrix, it is true, melts away before an electric current if it is in contact with the electrode; but this is not the condition in certainly a very large proportion of these cases. There is no real analogy between a stricture at the meatus, due to ulceration and destruction of the mucous surface, and one deep down in the urethra resulting from the action of a chronic and 
persistent irritant of much less intensity. In very many of these cases the mucous membrane is quite intact; atrophied, it may be by pressure, but not destroyed. There has never been any ulceration; traumatic cases excepted, there is no superficial cicatrix, and the lining membrane is still capable of being dissected off and laid out its full width. "The exil* dation that causes the stricture lies in the submucous tissue and the layers outside this; much of it is a long distance off; and it has never yet been shown that an electric current js capable of causing the absorption of tissues that are not in contact with the electrode.

Internal urethrotomy stands on somewhat different ground. If the incision is sufficiently thorough (and it must traverse the whole length and depth of the stricture tissue) it relieves the urethra at once of the primary cause, but this is all it can do. There is no physiological rest for the inflamed tissues around; they are still kept in a state of constant irritation, not it is true by the tension of the stricture, but by the accumulation and retention of the secretion of the wound. Nutrition is still impaired, the chronic inflammation still persists ; and even if complications such as hæmor. rhage, urinary infiltration, and suppuration do not occur, more lymph is poured out, and later recontraction follows. At the best all that internal urethrotomy can do in a periurethral stricture is to insert a new longitudinal cicatrix in the middle of the old dense stricture tissue, without removing this.

External urethrotomy, on the other hand, is free from these drawbacks. The stricture, the original source of all the mischief, is divided thoroughly; hremorrhage, if it occurs, does no harm, as the blood is not retained and has no opportunity of decomposing in the wound; urinary infiltration is impossible, the exit is too wide; the drainage is perfect, and all the tissues around, freed from straining and every other kind of irritant, begin to recover at once. The deeper part of the inflammatory exudation undergoes fatty degeneration and becomes ab. sorbed ; the superficial, that which immediately borders the wound, owing to its feeble nutrition breaks down into pus and melts away; granulations spring up on either side, the tissues regain their natural texture, and by the time the wound is ready to close the whole of the dense mass is absorbed, and in its place there is merely a thin pliable scar in the middle line.

There are two drawbacks to this operation-both serious, especially in the case of private patients who do not wish to be confined for any length of time to their beds, or even to their rooms, by anything connected with a stricture. The one is that there is an external wound; many patients not unnaturally have a strong objection to being cut, as they express it; the other that whatever the prospect of permanent cure, immediate convalescence is undoubtedly more protracted, and there is the inconvenience in the mean. time of the greater part of the urine passing by an unusual ronte. For the rest, no other argument against it is of any weight. The immunity that it enjoys from all ordinary surgical complications is quite as great as, if not much greater than, that of internal nrethrotomy. Manifestly if it is reserved for cases in the last stage of all, in which other operations are impracticable, some allowance must be made for this. Rigors and urethral tever are less likely to occur. There is no need to tie a catheter in - a practice I have long since abandoned as most injurious, and without a single advantage in compensation. It is sufficient to pass one at the end of a week, and then every third or fourth day until the wound is sound (with cocaine injected down the urethra and into the wound the proceeding is quite painless), and the scar lying exactly in the middle line, and forming as it were a prolongation forwards of the median septum of the bulb, does not in any way interfere with the function of the corpus spongiosum.

There is one small point of interest in connexion with this which only further examination can settle. Both in Syme's and Harrison's cases-the only two in which I have been able to find an accurate record of a necropsy - the vrethra is described as being funnel-shaped at the seat of the old stricture, giving the impression that the floor had yielded. The coincidence is so remarkable that it seems to me not unlikely that the alteration in shape is due rather to the radial contraction of the scar left by the external wound drawing the floor down towards the skin, and thus affording an additional safeguard against recontraction.

The neglect of external urethrotomy appears to have arisen in great measure from the idea that strictures in the deeper parb of the urethra are the result of ulceration, like most of those at the meatus. In reality, although this may occur, it is the exception ; and the comparison between a cicatrix such as that left by the healing of an ulcer and the lymph that forms a peri-urethral stricture is very misleading. The one is due to suppuration, and if divided remains a cicatrix still without having lost (except for the moment) one particle of its power of contraction. The other is the outcome of long-continued chronic inflammation. So far as its pathology is concerned, a peri-urethral stricture is formed of lymph identical with that which makes its appearance in any other part of the body when it is subjected to the action of some slight persisting irritant. If the cause is removed, and no other is allowed to come in its place, the exudation slowly disappears and the tissues by slow degrees recover their normal condition of nutrition. So long as a stricture is confined to the mucous and submucous layers, it is possible that the indications may be fairly met by intra. urethral measures ; in the case of a peri-urethral strictare, one that can be felt from the outside, the anatomy of the part and the function of the urethra render this impossible without an external incision.

Note.-Since the above was written I have met with another case in which twenty.six years had elapsed since the operation. For many years the patient had not taken any precaution, but there was not the slightest sign of recontraction. Wimpole-street, $W$.

\section{CASES OF TUMOUR OF NERVE TRUNKS,}

\section{ILLUSTRATING THE RESULTS OF EXCISION OF THE TUMOUR ALONG WITH THE AFFECTED} PORTION OF NERVE.

By GEORGE H. HUME, M.D., F.R.C.S.ED., SURGFON TO THE ROYAL INFIRMARY, NEWCASTLE-ON-TYNE,

THE three cases which are the subject of this communication are identical only in the pathological character of the growth. In all it was sarcoma; and the tumour was so incorporated with the nerve fibres that it was impossible to dissect out the one from the other. The portion of nerve affected was therefore excised along with the growth, and in each case it comprised the whole thickness of the nerve. In two of the cases the great sciatic nerve was the seat of tumour, in the third the internal popliteal. In the first case no attempt was possible to suture the nerve, and an illustration was afforded of the condition of a limb as regards maintenance of nutrition and usefulness, after resec. tion of a portion of its chief nerve trunk. In the second case of sciatic tumour a successful partial suturing of the trank was effected, notwithstanding the wide separation of the ends. The case of tumour of the internal popliteal, which has already been noticed in THE LANCET, is again brought forward as an instance of that most interesting and still unexplained phenomenon of gradual regeneration and restoration of function in a nerve whose continuity has been interrupted by the excision of a not inconsiderable portion.

CASE 1. - Francis B-_, aged twenty-four, was admitted into the Newcastle-on-Tyne Infirmary on Jan. 24th, 1888, on account of a tumour at the back of the left thigh. The lump had been noticed for five months. It extended from the fold of the buttock to the upper part of the ham, being ovoid in shape and movable from side to side, but not from above downwards. There was a good deal of pain below the knee and in the foot, so aggravated at night as to prevent sleep. The calf of the affected leg meassured seven-eighths of an inch less than the right. There was no impairment of motion or loss of sensibility. A few days after admission the tumour was removed. The lower border of the gluteus maximus required division in order to get beyond the disease superiorly, and the lower section of the nerve was made at the upper limit of the ham. The tumour was easily shelled out. The wound healed rapidly, and in a month the patient was able to walk about without any support. The growth was found to be 